\title{
Multipurpose Retrofitting of a Tower Building in Brescia
}

\author{
Giuliana Cardani ${ }^{1, *(D)}$, Gian Ermes Massetti ${ }^{2}$ and Davide Riva ${ }^{3}$ (D) \\ 1 Department of Structural and Environmental Engineering, School of Architecture, Politecnico di Milano, \\ 20133 Milan, Italy \\ 2 Studio Ingegneria Strutturale Massetti, Associato Re_Load-Cremona, 26100 Cremona, Italy; \\ ing.massetti@studiomassetti.it \\ 3 Studio Ing. Davide Riva, Associato Re_load-Brescia, 25045 Castegnato, Italy; davriva@libero.it \\ * Correspondence: giuliana.cardani@polimi.it; Tel.: +39-02-2399-4204
}

Citation: Cardani, G.; Massetti, G.E.; Riva, D. Multipurpose Retrofitting of a Tower Building in Brescia. Sustainability 2021, 13, 8877. https:// doi.org/10.3390/su13168877

Academic Editors: Maria Rosa Valluzzi and Angelo Masi

Received: 15 June 2021

Accepted: 2 August 2021

Published: 9 August 2021

Publisher's Note: MDPI stays neutral with regard to jurisdictional claims in published maps and institutional affiliations.

Copyright: (c) 2021 by the authors. Licensee MDPI, Basel, Switzerland. This article is an open access article distributed under the terms and conditions of the Creative Commons Attribution (CC BY) license (https:/ / creativecommons.org/licenses/by/ $4.0 /)$.

\begin{abstract}
The paper aims to report a proper low-impact integrated study approach for the energy and seismic retrofitting of a tower building located in the city centre of Brescia (Italy). The building consists of a group of aggregate buildings built in the 1950s, from which emerged an 11-storey tower. It was built with the technology of the time by means of a perimeter and spine framed structure in reinforced concrete, double perimeter infill with a hollow brick air chamber, external cladding on the main fronts with small Botticino marble tiles. The building is registered by the Ministry of Cultural Heritage for its facade and is located in a seismic zone of category two. When work began, the construction was in a class three; thus, the whole project was updated to obtain the new seismic authorisation. The coating showed progressive decay, with dangerous structural instability of the heavy coating. The design team decided to adopt wider corrective action compared to the observed phenomenon, integrating it with a local seismic and global energy improvement through the insertion of a ventilated wall in the building and the realisation of accurate thermal and energy insulation systems. At the end of the intervention, this building became the first condominium in Italy in 2018, certified in class A and upgraded with sustainability criteria in which the application of the GBC Italy (Green Building Council) Condominiums protocol, currently in its final publication phase for the energy-environmental sustainability of condominiums, has been tested.
\end{abstract}

Keywords: modern built heritage; energy retrofitting; local seismic retrofitting; integrated approach; ventilated façade

\section{Introduction}

The paper intends to report a proper low-impact integrated study approach for the seismic and energetic improvement of a tower building located in the centre of the city of Brescia in Lombardy, Italy, seismic class 2. Work began in 2016, following a multidisciplinary design approach involving several professional authorities in the various fields (structures, energy, installations, fire prevention, safety, etc.).

The building was also the object of application, as a case study, of the first version of the GBC (Green Building Council) Condominiums energy-environmental protocol, with the aim of verifying the applicability of this specific rating system, which was newly drawn up by the Green Building Council Italia [1]. Here, in addition to the traditional environmental energy components-also found in other systems such as LEED or BREEAM-there is a specific area on building durability and resilience. These aspects are included in the GBC Condominiums rating in order to support the analysis and management of the risk associated with extreme structural and climatic phenomena, for which the existing building being upgraded was not originally designed, and therefore, to make conscious upgrading choices. 


\section{The Area of Intervention: The City of Brescia}

Brescia is a city of about 200,000 inhabitants; it is one of the main economic-productive areas in Italy, with an important historical stratification of at least 3000 years. Brescia is also a city dedicated to experimentation. Italy's first reinforced concrete house was built in 1898: Casa Migliorati, designed and built by architect and engineer Egidio Dabbeni [2]. In the 1930s, Brescia achieved primacy by building, in 1932, the tallest skyscraper in Italy and, during that time, the tallest reinforced concrete skyscraper in Europe: the INA tower (arch. M. Piacentini in collaboration with Eng. L. Campagna and Eng. A. Danusso). Located in the heart of the historic town centre, in Piazza Vittoria, and created by the demolition of a medieval quarter, the building was constructed with a height of $57 \mathrm{~m}$ and became the symbol of the verticality of fascism [3,4].

In the post-war period, Brescia continued to grow both horizontally and, from the 1980s, also vertically, continuing to modify its skyline. The skyscraper increasingly became the supreme icon of Brescia's modernity [3].

\section{Seismicity of the Area}

The main known seismic events that have affected the city of Brescia in historical times are: year 1065 (magnitude $M=5.2)$, year $1117(M=6.5)$, year $1222(M=5.9 / 6.8)$, year 1471 $(\mathrm{M}=4.2)$, year $1521(\mathrm{M}=4.4)$, year $1540(\mathrm{M}=4.4)$, second half of the seventeenth century ( $M=5.7)$. Until 2003, Brescia was not included within the perimeter of the areas subject to seismic risk. With the Ordinance O.P.C.M. 20.3 .2003 n. 3274 [5], a new classification of seismic risk for all municipalities of the national territory, Brescia passed to zone three, which corresponds to a classification of "low seismicity". This ordinance was updated with the Deliberation of the Regional Council of Lombardy of 11 July 2014 n. 2129 [6], which drew up a new seismic classification of the Lombardy territory with the aim of determining a more precautionary level of classification; with its entry in force on 10 April 2016, it brought Brescia into zone two: "Zone with medium seismic hazard where strong earthquakes may occur".

\section{The Tower Building under Study}

The 11-storey building under requalification is privately owned and was built in the 1950s in the historic town centre of Brescia, in the place of the former historic building intended to house wares [7], in A. Gramsci Street, on the corner with Vittorio Emanuele Street. It consists of three different blocks, which comprise house residential housing and offices. The tallest tower is 11-storeys $(36.50 \mathrm{~m})$, built with a perimeter and spine structure of reinforced concrete frames, double perimeter infill with brick planks with air space, external cladding on the main fronts with Botticino limestone tesserae, typical of the area and commercially known as marble, and black stone marble slabs (Figure 1).

Initially, the problem was due to the obvious signs of decay on the facade cladding, which had been damaged in several places by the weather and smog. The areas that showed swelling and no longer bonded to the wall had caused some of the wall tiles to detach, causing great concern to the owners of the property that they might fall off. Since the building is located in the town centre of Brescia, in a busy area of high traffic, and is also subject to the restrictions of the local supervisors of the Ministry of Cultural Heritage, the resolution of this initial problem was necessary, and the study was started to avoid risks to passers-by and to guarantee their safety. The initial study then identified certain corrective actions that were more substantial and remedial than the observed phenomenon, integrating this with possible local seismic and global energy improvement through the insertion of a ventilated wall in the building and the implementation of accurate thermal and energy insulation systems. 


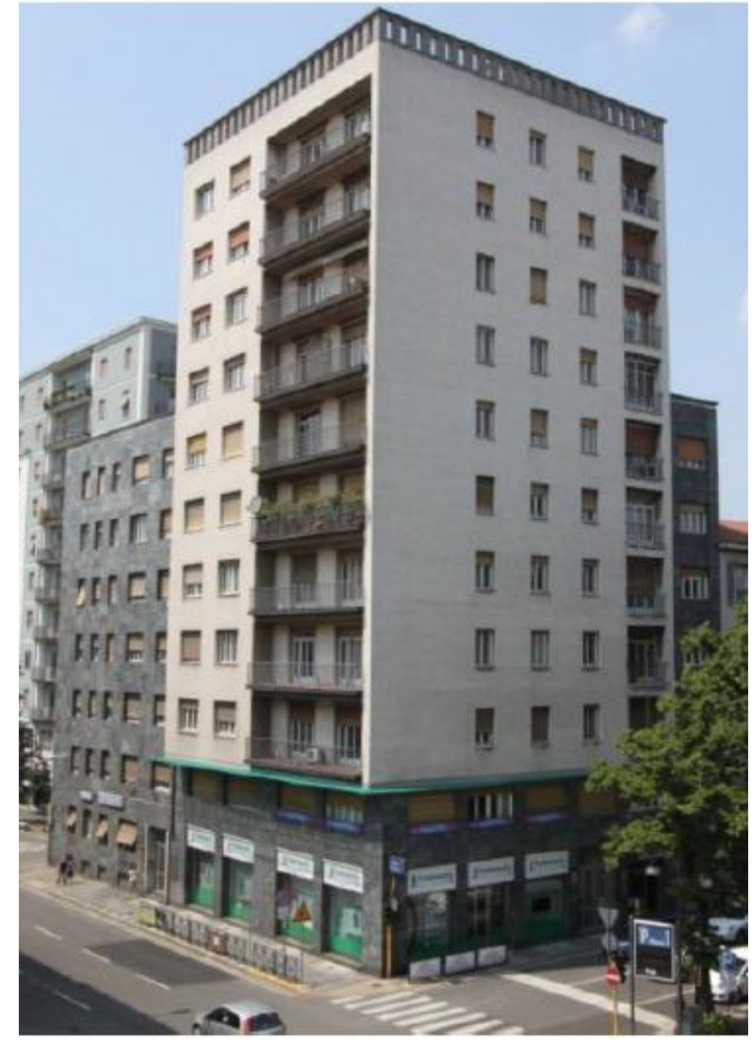

(a)

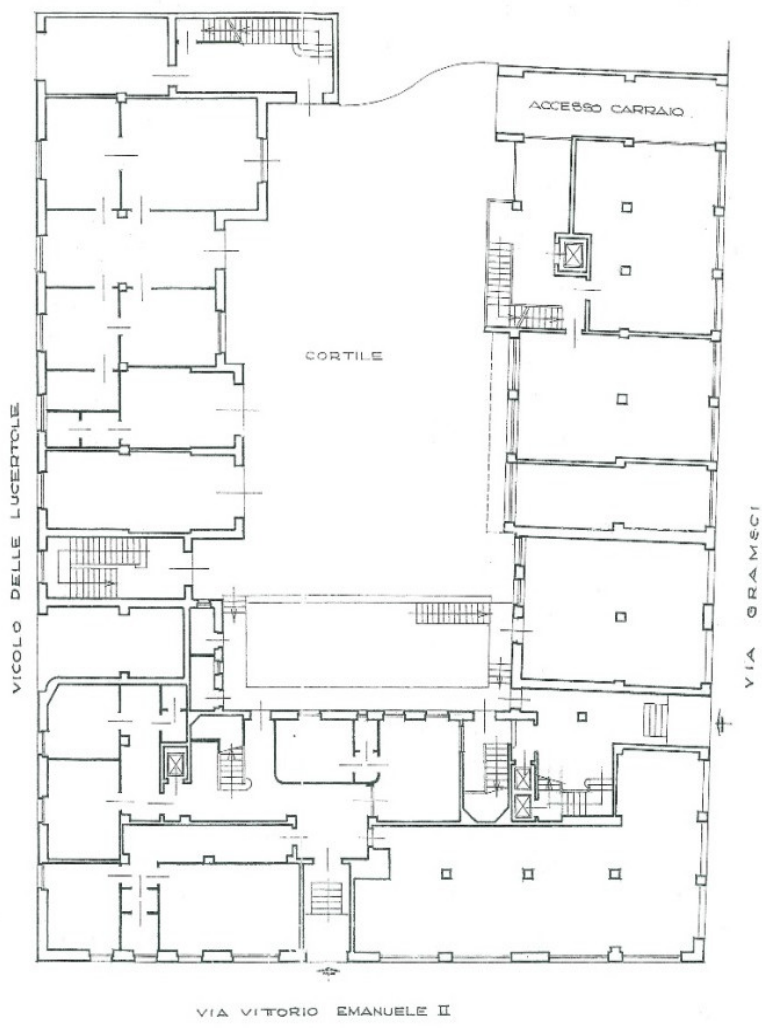

(b)

Figure 1. The 1950s tower building in Brescia: (a) before the intervention and (b) original plan of the complex. The bottom-right corner is the 11-storey tower.

The additional value of this project is also to be found in the organisation of the site and the planning/execution of the works. Since this was an almost entirely rented building, consisting of commercial activities on the ground floor and the prevalence of offices on the upper floors, the need was to maintain the effective usability of the rooms by the tenants during working hours, adapting the life of the site with that of the employees.

\section{Preliminary Diagnostic Investigations}

The project was launched thanks to a wide-ranging, diversified, tested and flexible multidisciplinary technical panel, in which the owners' tax experts collaborated by way of appropriate analyses for a prodromal initial assessment of technical and economic feasibility and convenience, linked to both risk factors and tax benefits. On the basis of the preliminary feasibility study, an executive diagnostic project was carried out to acquire adequate knowledge of the building. Subsequently, the project was developed through the preliminary, definitive and executive phases; a project for overall retrofitting that would also integrate the architectural features as well as the energy and local seismic features, with interventions carried out only on the exterior of the building and with low environmental impact.

In the first analysis, a detailed series of diagnostic investigations was carried out to gain knowledge of the mechanical characteristics of the structures (for the reinforced concrete structures, ultrasonic investigations, coring, magnetometric tests, pull-out) and due to the absence of structural executives, a simulated design of the structures was carried out, placing the construction at a LC2 level of knowledge with a confidence factor of FC2 $=1.2$, according to [8].

The importance of the results of this structural analysis to the development of subsequent project activities has confirmed the feasibility and usefulness of the contents in the 
"Durability and Resilience" section of the GBC Condominiums protocol, which requires analyses similar to those described here.

\section{Energy Efficiency of the Building}

The building consists of three distinct blocks (Figure 2) built at different times, between the mid-1940s and 1950s, served by two thermal power stations connected to the city district heating system using superheated water, produced by A2A power stations. See Figures 2 and 3.

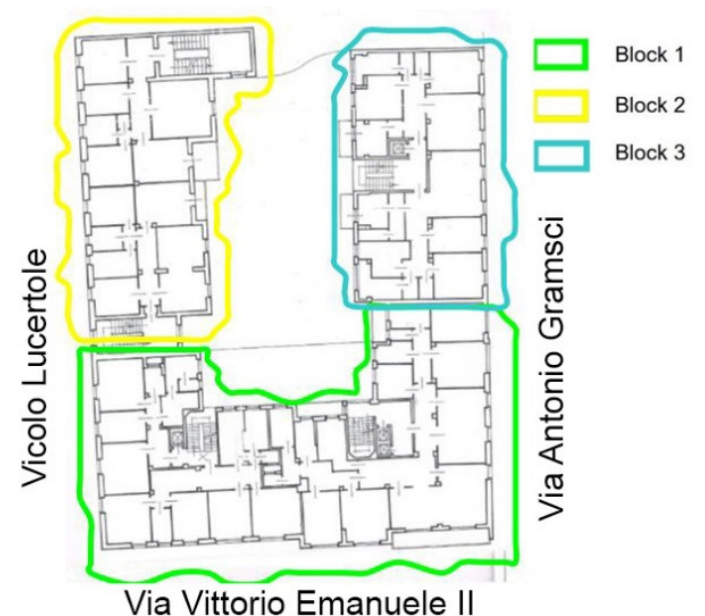

Figure 2. Definition of the building blocks covered by the energy diagnosis.

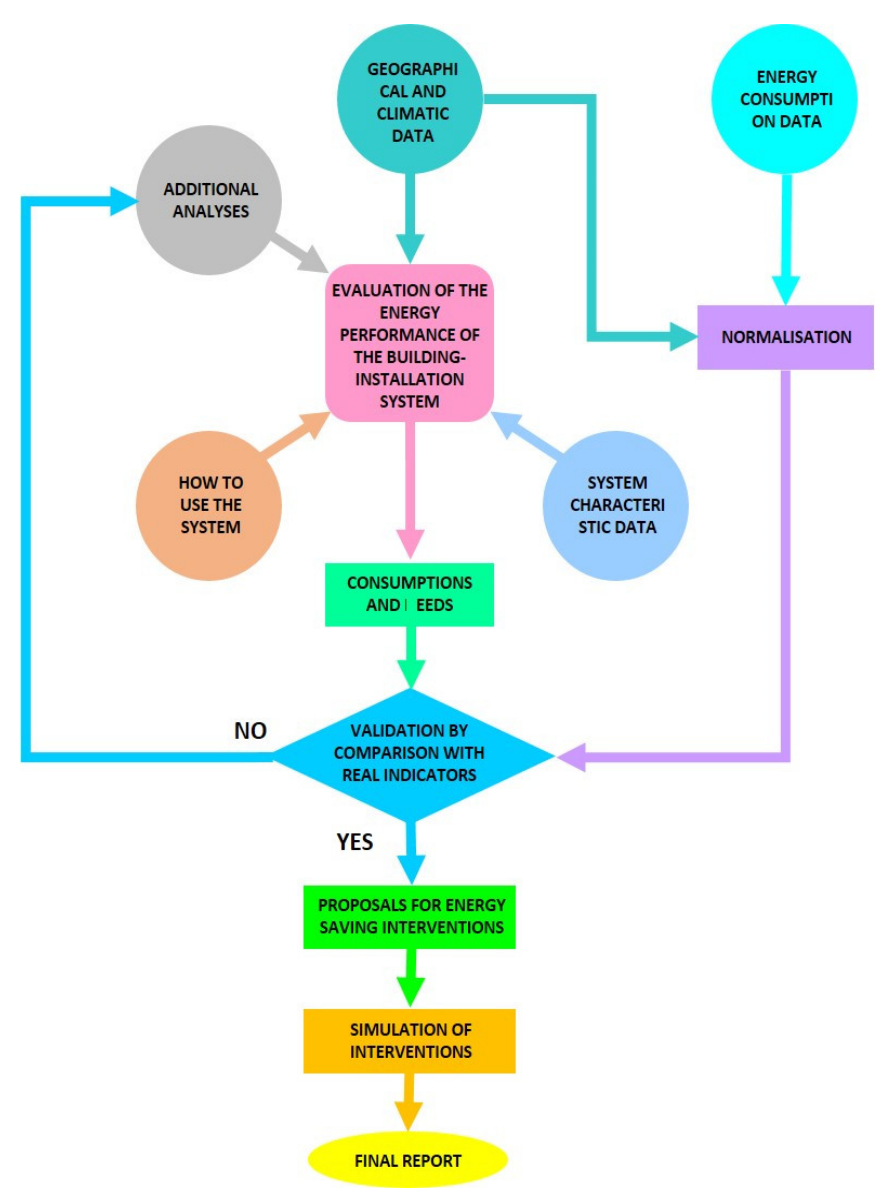

Figure 3. Definition of the Energy Audit methodology. Figures based on [9]. 
In Table 1 some dimensional characteristics of the building are reported.

Table 1. Dimensional characteristics of the building blocks.

\begin{tabular}{|c|c|c|c|}
\hline Structural characteristics of the building & Net Area & 1545.54 & $\mathrm{~m}^{2}$ \\
\hline \multirow{4}{*}{$\begin{array}{l}\text { Central heating plant in Gramsci St. n. } 28 \\
\qquad(\text { Blocks } 2+3)\end{array}$} & Gross external Area & 3102.32 & $\mathrm{~m}^{2}$ \\
\hline & Net Volume & 4965.34 & $\mathrm{~m}^{3}$ \\
\hline & Gross Volume & 6761.32 & $\mathrm{~m}^{3}$ \\
\hline & A/V Ratio & 0.46 & $\mathrm{~m}^{-1}$ \\
\hline \multirow{5}{*}{$\begin{array}{l}\text { Structural characteristics of the building } \\
\text { Central heating plant in Vittorio Emanuele II St. } \\
\text { n. } 43 \text { (Block } 1)\end{array}$} & Net Area & 3983.10 & $\mathrm{~m}^{2}$ \\
\hline & Gross external Area & 6342.03 & $\mathrm{~m}^{2}$ \\
\hline & Net Volume & $12,061.88$ & $\mathrm{~m}^{3}$ \\
\hline & Gross Volume & $16,111.56$ & $\mathrm{~m}^{3}$ \\
\hline & $\mathrm{A} / \mathrm{V}$ ratio & 0.39 & $m^{-1}$ \\
\hline
\end{tabular}

It should be reported that the energy upgrade was carried out on the building called Block 1.

The group of professionals in charge of the energy project had the specific task of assessing the status of the thermal insulation performance of the existing envelope in order to identify the most suitable intervention in order to achieve greater internal comfort in the working and residential environments in compliance with the parameters imposed by the regional legislation on energy saving in force at the time [10].

The energy diagnosis was then drawn up, starting from a validated "baseline", from which the different project hypotheses presented to the client were derived (Figure 3). With regard to the vertical and horizontal opaque structures, the critical points (such as lack of insulation, discontinuities in thermal resistance due to the geometry of the building and the presence of uninsulated supporting structures) were analytically assessed and the significant surface temperatures were studied before and after the intervention, in line also with the current code on energy efficiency DM 26/06/2015 [11] and subsequent amendments and additions; then the materials, the thickness of the insulation and the construction techniques were identified, also aimed at correcting the thermal bridges detected.

The calculation of the dispersion of the opaque and transparent elements was carried out using a specialist software for calculating energy performance in steady state, in accordance with the relevant technical specifications. During the design phase, studies on the behaviour of the envelope were also carried out using dynamic simulation software (Energy Plus, Figure 4). The most critical nodes were simulated with a two-dimensional finite element software, validated according to UNI 10211:2008 [12], in order to control surface temperatures and linear dispersions caused by thermal bridges.
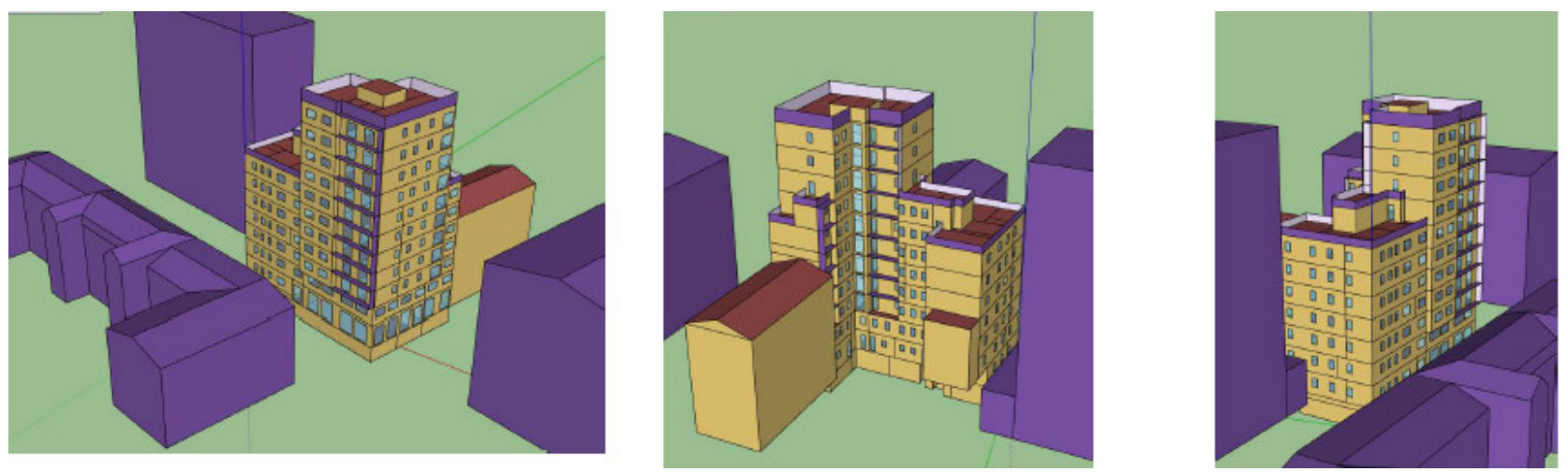

Figure 4. Dynamic energy simulation of the building envelope with a 3D interface. 


\subsection{Energy Diagnostic Investigations}

Thermographic Surveys

As part of the initial survey, in order to assess the state of the sites and obtain the necessary data for the preliminary study of the design proposals, a detailed inspection of the opaque surfaces of the structures was carried out using infrared thermography to survey the surface characteristics of the walls (Figure 5). This investigation was carried out by personnel qualified to the second level in non-destructive testing (NDT) and conducted according to the reference standards, UNI EN ISO 9712:2012 [13]. As is well known, thermography is a diagnostic technique that measures the infrared radiation emitted by bodies, and then returns a two-dimensional representation of the surface temperature distribution. This provides highly significant data on which to base corrections and implementations.

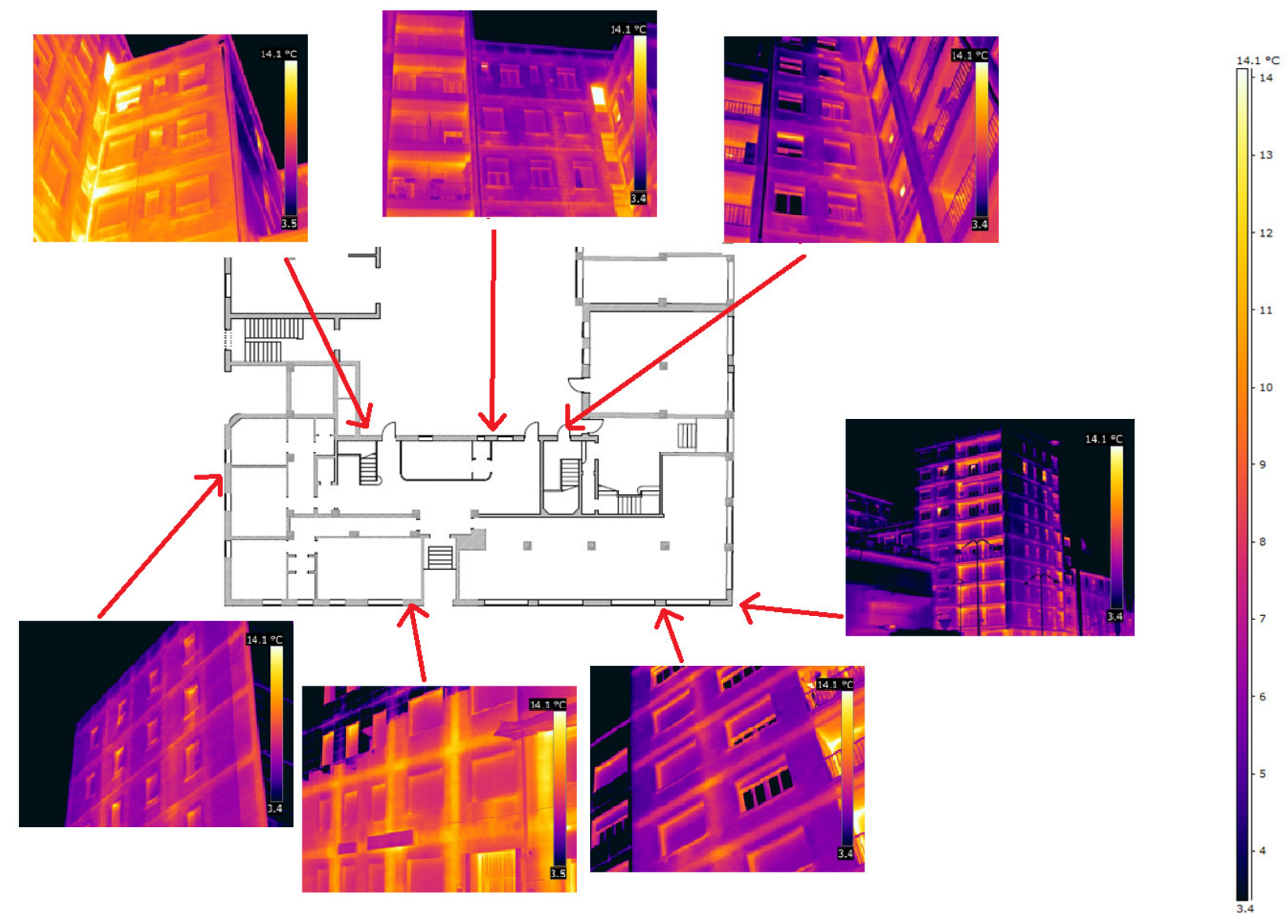

Figure 5. Plan of the building Block 1 and some reference thermograms.

The thermographic survey provided results in two distinct phases: the first thermographic survey was carried out ante operam, to survey the existing state and before the laying of the "insulation system". The second thermographic survey was carried out post operam, at the end of the works and after the laying of the insulation system, to obtain the certification and verify that there were no errors in the execution.

\section{(a) Winter analysis}

In order to determine the thermal fluxes, the existing building elements examined include, for example, masonry, architectural cantilevered parts, window frames, docks and boxes. The different stratigraphy was observed during surveys, site investigations and during demolition operations.

The typical local winter season weather statistics were considered: (a) conventional period of heating: 183 days; (b) winter project temperature: $-7^{\circ} \mathrm{C}$; (c) altitude: $149 \mathrm{~m}$ a.s.l., 
(according to the code: UNI 10349:2016 which provides, for the Italian territory, the conventional climatic data needed to verify the energetic and thermo-hygrometric performance of buildings, including the technical systems for summer and winter air conditioning in use [14]).

The simulation of the thermal flows shown in the diagram in Figure 6a represents the surface temperature trend in the actual state. It will be noted that the presence of the reinforced concrete slab and the high transmittance of the internal wall contribute to lowering the surface temperature, a problem encountered above all at the corners between the wall and the floor. It is well known that surface temperatures below $16{ }^{\circ} \mathrm{C}$ lead to thermal discomfort and the risk of mould and condensation forming.
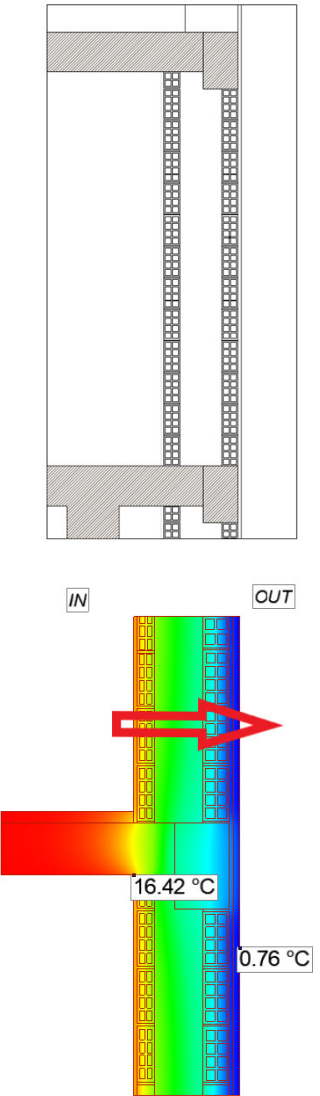

0.00

(a)
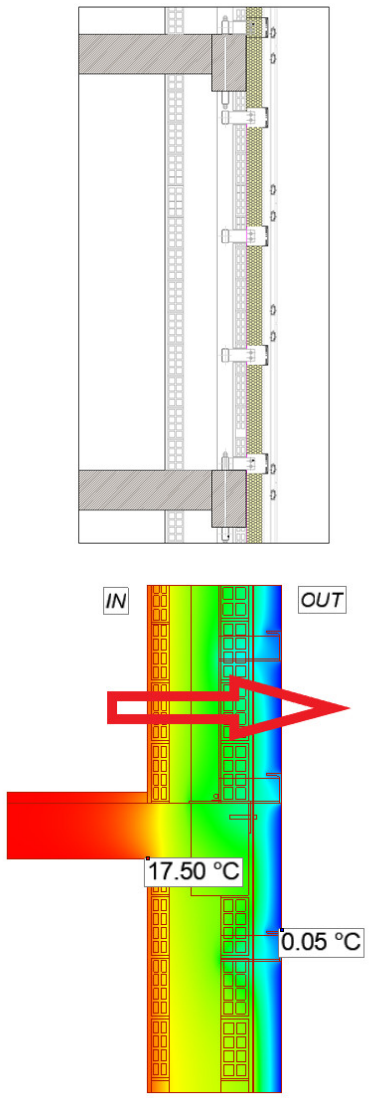

19.96

(b)

Figure 6. (a) On the left, detail of the hollow core masonry, typical of the construction period; on the right the finite element heat flow simulation. (b) On the left, detail of the hollow core masonry after thermal insulation and ventilated façade and, on the right, the finite element heat flow simulation.

The application of rock wool insulation under the ventilated façade, with a density of $70 \mathrm{~kg} / \mathrm{m}^{3}$ and a thickness of $12 \mathrm{~cm}$, which is highly breathable, allows surface temperatures of over $18{ }^{\circ} \mathrm{C}$ to be reached and guarantees good hygrometric behaviour of the masonry, as shown in Figure 6b.

This material is completely incombustible, in accordance with the rules of the circular issued by the National Fire Brigade, Prot. No. 0005043 of 15/04/2013, Guide for the determination of "Fire safety requirements for facades in civil buildings" [15].

In the examination at the façade overhang point, extremely low internal surface temperatures were found at the outermost corner (Figure 7a). The design study identified 
the correct product to raise the temperature of this critical node, contributing to a significant improvement in the comfort of the rooms affected by limiting heat loss (Figure 7a,b).
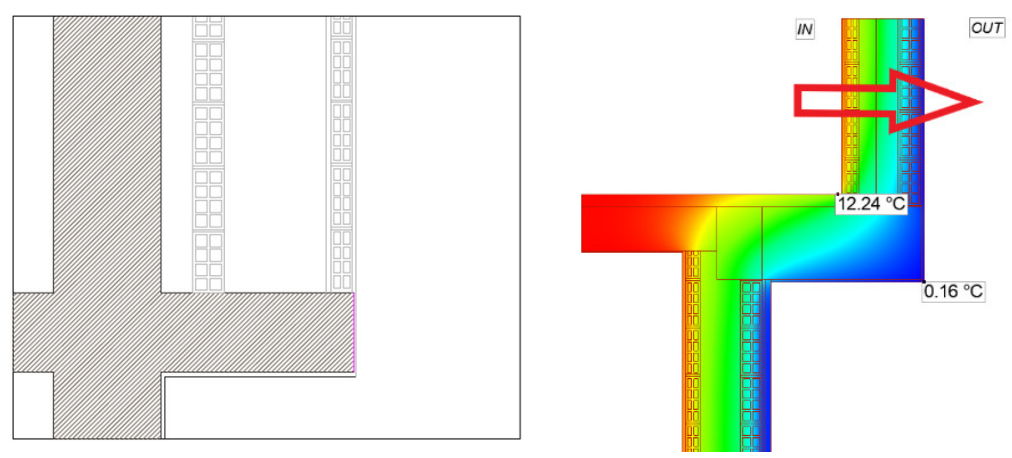

(a)
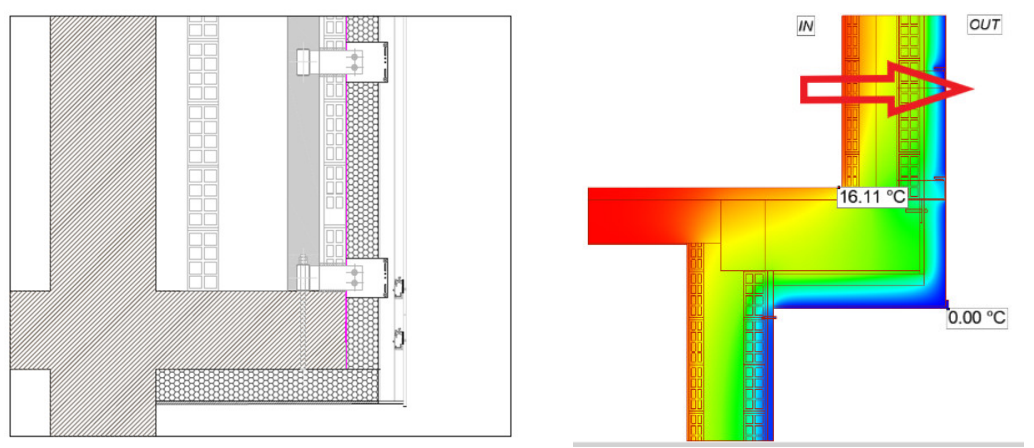

(b)

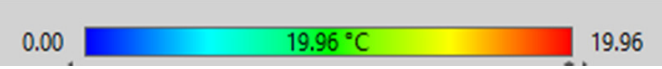

Figure 7. (a) On the left, detail of the façade overhang, typical of the construction period, and, on the right, the finite element heat flow simulation. (b) On the left, detail of the overhang after thermal insulation and ventilated facade work and, on the right, its finite element heat flow simulation.

Correcting the thermal bridges in the existing windows and doors, which had already been replaced between 2007 and 2013, proved to be one of the most delicate aspects of the project. Almost all the windows and doors were PVC framed and double-glazed with low-E glass, and the new frame was fitted over the existing one. This required a certain amount of attention, especially regarding the behaviour of the connection points to the masonry.

Another critical point was the insulation of the lower pier (Figure 8). As the detail in Figure 8a shows, the window and doorframe rests on a stone sill. This type of fixing prevents the stone from being removed or cut during the execution of the works. The thermal analyses carried out indicate that the surface temperatures at these points are extremely low (around $10^{\circ} \mathrm{C}$ ). The design solution identified was to cover the existing sill with an ultra-thin, hydrophobic, nano-porous aerogel-based insulation panel (high thermal characteristics $\lambda=0.015 \mathrm{~W} / \mathrm{mK}$ ) of low thickness, in order not to interfere with the condensation drain of the existing window frame. This intervention allows raising the internal surface temperature of the edge of the existing dock by about $6 / 7^{\circ} \mathrm{C}$ (Figure $8 b$ ). Some positive results are reported in Table 2. 

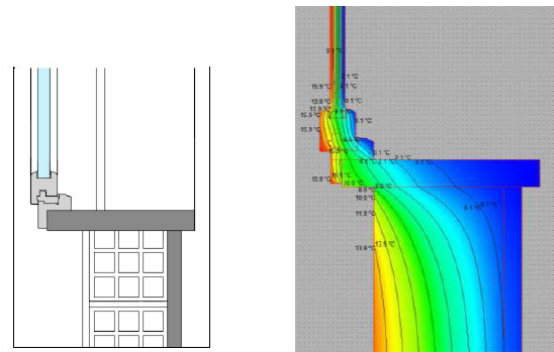

(a)

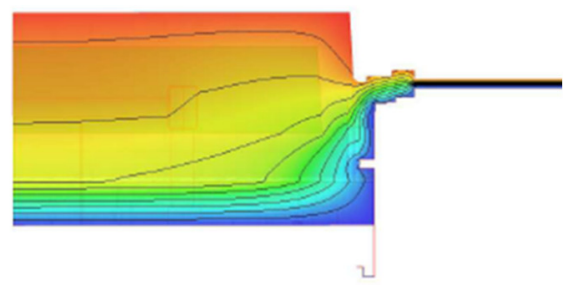

(c)

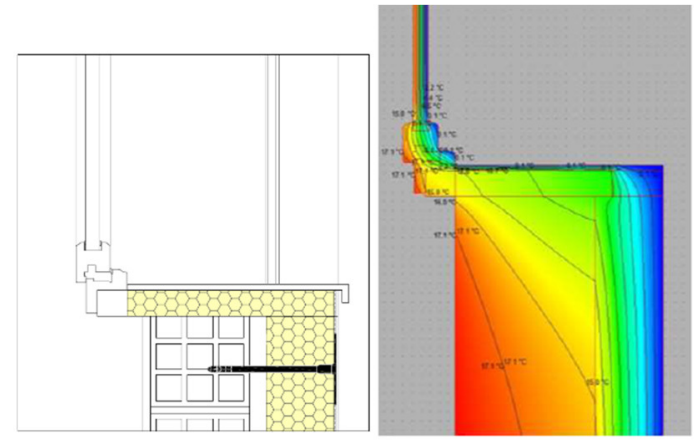

(b)

Figure 8. (a) Detail of windowsill node, typical of the construction period, on the left; finite element heat flow simulation on the right. (b) Detail of windowsill joint after intervention on the left; finite heat flow simulation on the right, as well in (c).

Table 2. Pre- and post-intervention U-Values.

\begin{tabular}{ccc}
\hline Element & $\begin{array}{c}\text { U-Value before Intervention } \\
{[\text { W/mqK] }}\end{array}$ & $\begin{array}{c}\text { U-Value after Intervention } \\
{[\text { W/mqK] }}\end{array}$ \\
\hline Facade & 0.987 & 0.211 \\
\hline Flat roof & 0.570 & 0.202 \\
\hline
\end{tabular}

\section{(b) Summer analysis}

For the behaviour of the envelope in the summer period, energy analyses were carried out using the PAN software of ANIT (National Association for Thermal and Acoustic Insulation). The typical local summer season weather statistics were considered: (a) summer project temperature: $+31.8^{\circ} \mathrm{C}$; (b) daily thermal excursion: $15^{\circ} \mathrm{C}$ (according to the code: UNI 10349:2016 [14]).

Considering both the existing wall and the design wall in a dynamic regime, the application of thermal insulation (medium-high density materials), with a ventilated façade above, proved to be advantageous in terms of lowering the internal surface temperature. In the diagram below, in the image on the right, it results that the internal surface temperature before the intervention was higher than $30^{\circ} \mathrm{C}$ (Figure 9a). Figure $9 \mathrm{~b}$ shows the dynamic simulation of the design hypothesis: insulation of the existing hollow core masonry and the application of the ventilated wall.

As it can be observed from the diagram (Figure 9b), the application of the ventilated façade and the insulating material leads to a decrease in the surface temperature on the inner side of the masonry, with undoubted advantages to the quality of thermal comfort in hot weather.

In addition, in order to limit the energy requirements for summer air conditioning and to contain the internal temperature of the rooms, external screening and shading systems have been installed (sunshades and high-density insulated aluminium roller shutters), which reduce the contribution of heat by radiation through the transparent structures, which currently have a solar factor g of around 0.55-0.60 (Figure 10). 

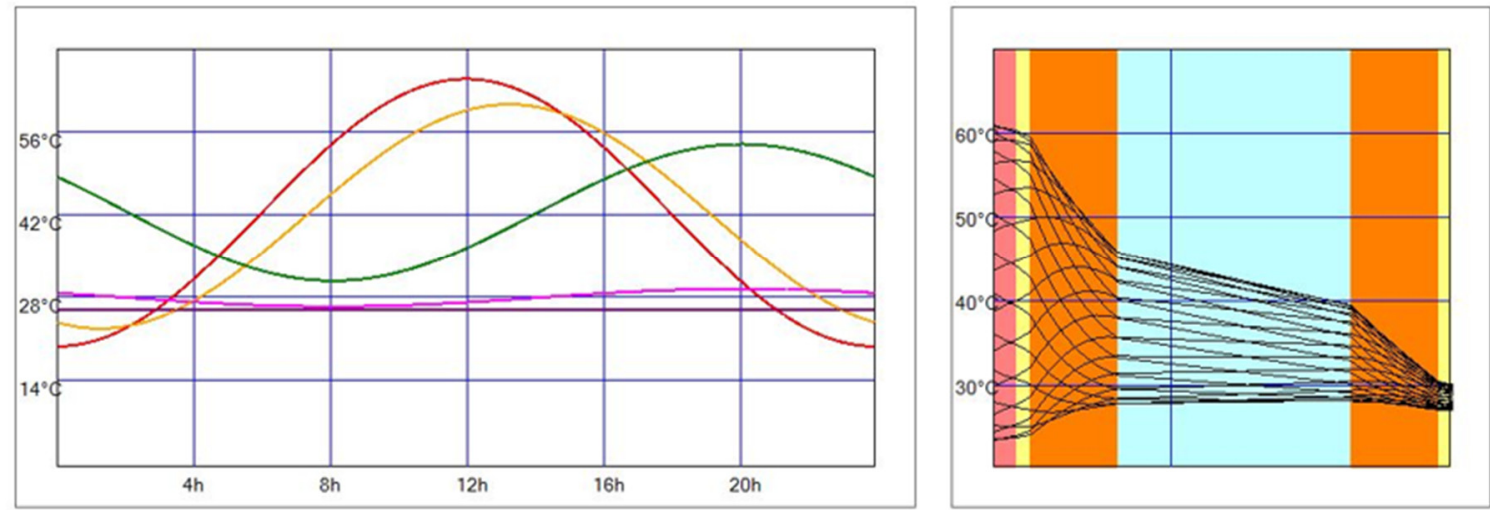

(a)
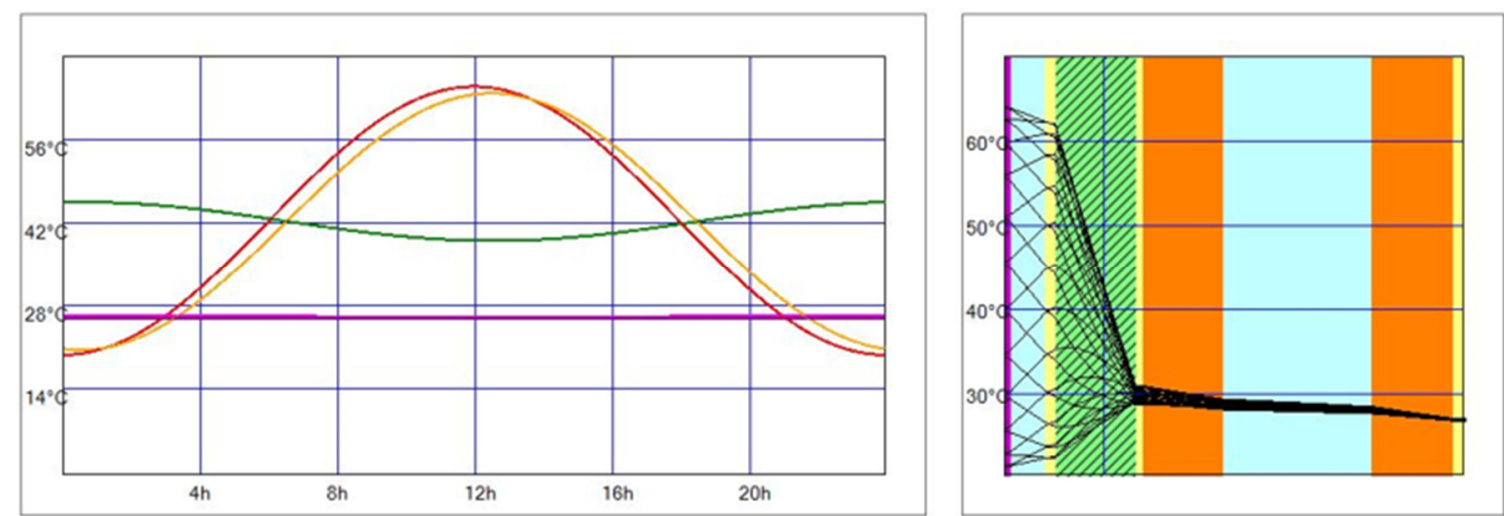

(b)

\section{Outside Ext. Sup. Stat. Int. Sup. Inside}

Figure 9. Analysis of the summer condition of the wall: (a) before intervention and (b) after intervention.

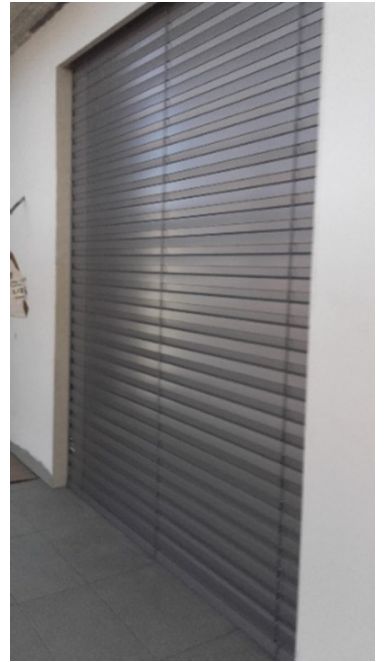

(a)

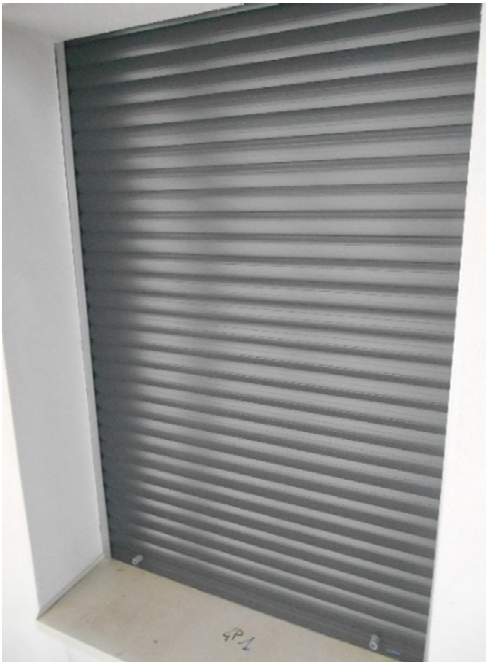

(b)

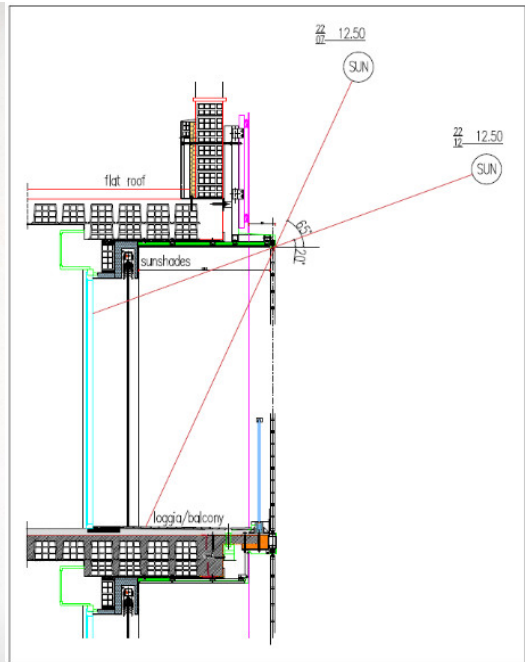

(c)

Figure 10. (a) External Venetian blind shading system, (b) roller shutter and (c) solar study scheme to test the effectiveness of loggias in shielding solar radiation in summer (typical summer day: 22 July) and allowing it to penetrate in winter (typical winter day: 22 December).

It was also agreed to proceed with the insulation of the solar slabs through the laying of a vapour barrier on the structural floor and overlying thermal insulation made of polyiso 
foam material with an excellent thermal conductivity value and specific heat, obtaining a periodic thermal transmittance of $0.028 \mathrm{~W} / \mathrm{m}^{2} \mathrm{~K}$, and low attenuation values of the thermal wave. To complete the package, a sheath with an external surface finish made up of white slate micro-scales for "Cool Roof" type roofs was laid on the slope screed.

\subsection{Desgin Proposals}

Following the results of the energy assessment, several design hypotheses were analysed. It was decided to adopt the insulated ventilated wall on the south-east and west facades. On the north wall, in the inner courtyard, a $12 \mathrm{~cm}$ rock wool thermal insulation was applied in continuity with the plastered finishing of the adjacent buildings.

The ventilated façade is a special type of cladding that involves, on the external surface of the building, the dry application of panels of a suitable thickness, mechanically fixed to a support structure anchored to the masonry. Thanks to mechanical fixing, the walls of buildings can be safely covered with materials of different types, shapes and colours to give them a precise architectural image. In terms of energy, the most interesting feature is the position of the external cladding layer, which does not adhere to the infill wall but is distanced from it. This allows natural air circulation in the cavity space due to the convective motion produced by the presence of openings at the base and summit of the façade.

In this case, this technique allowed the façade to be modernised, thermally insulated and architecturally enhanced. The choice of finish, size, colour and material appearance was discussed with the supervisors of the Ministry of Cultural Heritage in order to better adapt the visual impact to the surrounding context.

The application of ventilated façades has required a specific design, which has carefully considered thermal exchange and the creation of construction details to ensure correct operation. Various considerations were made regarding the type of fixing, (concealed, exposed, etc.) and the shapes and colours of the tiles. In addition to thermal and aesthetic aspects, great attention was paid to safety. Products and fixing systems were carefully researched in order to guarantee the installation and durability of the components and to avoid the problem of the detachment of the covering.

Of the many benefits achieved:

1. In the winter period, the heat is better retained inside the premises thanks to the thermal insulation layer applied to the masonry.

2. In the summer period, the internal walls are insulated from direct solar radiation, disconnected by a layer of air, and the surface radiated by the sun. This is, in fact, an existing building constructed using the "hollow core", named in Italian "cassavuota", a technique considered with a non-ventilated air space $\left(\mathrm{Av}<500 \mathrm{~mm}^{2} / \mathrm{m}\right)$, but not sealed. The temperature remains lower, and more comfort is created inside the premises;

3. Acoustic insulation is improved through the combination with fibrous insulation materials;

4. The thermal insulation layer is better protected against humidity from outside and against considerable temperature changes, ensuring a longer life span.

In addition to the energy aspect of reducing consumption, great attention was paid to the concept of internal comfort, both thermal and the illumination, as the building is mainly occupied by offices. Since the tower is completely south-facing and, given its height, free from shading obstacles, the contribution of solar-controlled shading guaranteed optimal light conditions inside the rooms, as well as protection from overheating through the windows (by means of shutters with adjustable sunshades and mobile sunshades on the south-facing loggias).

At the end of the redevelopment, the results in terms of efficiency and energy savings were evident: the building went from $544,780 \mathrm{kWh}$ before the redevelopment to $233,580 \mathrm{kWh}$, with a decrease in consumption of $57 \%$ and a significant economic saving (Table 3). The resulting cost saving, net of the fixed fees due to the energy supplier and 
which represent about $35 \%$ of the cost of the bill, is about $35 \%$ or more than EUR $15,000.00$ per year.

Table 3. Efficiency and energy-saving results after and before the intervention for Block 1 .

\begin{tabular}{|c|c|c|c|}
\hline Year & Month & Thermal Energy Bill & Thermal Energy Bill \\
\hline & & Post Operam & Ante Operam \\
\hline- & - & {$[\mathrm{kWh}]$} & {$[\mathrm{kWh}]$} \\
\hline 2018 & October & 12,730 & \\
\hline 2018 & November & 39,760 & \\
\hline 2018 & December & 48,180 & \\
\hline 2019 & January & 60,420 & \\
\hline 2019 & February & 34,460 & \\
\hline 2019 & March & 28,460 & \\
\hline \multirow[t]{2}{*}{2019} & April & 9570 & \\
\hline & Total & $233,580($ reduction $=57 \%)$ & 544,780 \\
\hline
\end{tabular}

It was not possible to assess the energy savings for cooling as there is no centralised summer air conditioning and several units do not have cooling systems.

The thermograms in Figure 11 demonstrate the effectiveness of the thermal insulation work carried out: the heat losses of the opaque structures have been practically eliminated. The APE Energy Performance Certificates of the single building units, drawn up at the end of the works, were made with the CENED procedure currently in force in the Lombardy Region, according to Decree 30.7.15 N6480 [16]. The energy class achieved after the intervention was A.

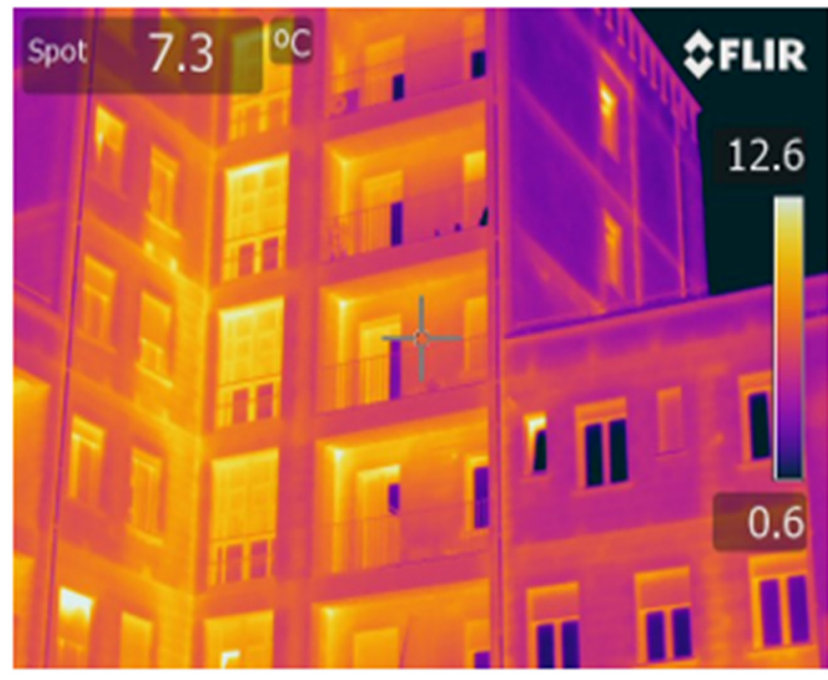

(a)

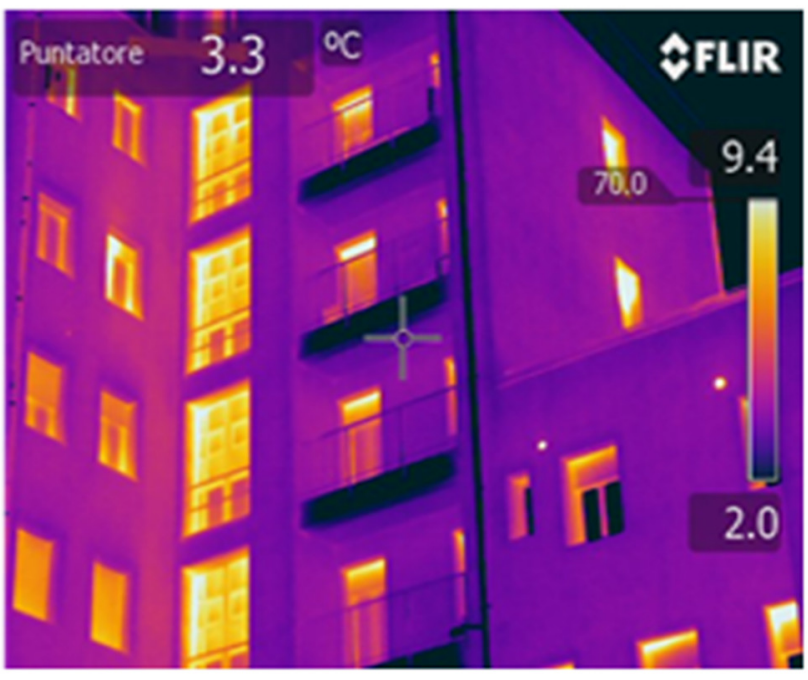

(b)

Figure 11. Thermogram: (a) before work; (b) after work.

As previously mentioned, this was also the first condominium in Italy in 2018 to be upgraded with sustainability criteria in which the application of the GBC Condominiums protocol, currently in its final publication phase, for the energy-environmental sustainability of condominiums has been tested. The executive project and the subsequent on-site works have been validated by accredited external and third-party bodies with serious and proven expertise at a national level (pre- and post-intervention thermography carried out by third level thermographers from ANIT's engineering company). In particular, the 
energy diagnosis process followed has highlighted the feasibility and usefulness of the requirements contained in the GBC Condominiums protocol in terms of energy analysis, which together with the protocol's requirements in terms of structural analysis, allow all those involved in the redevelopment to make informed choices in terms of costs and benefits (Figure 12).

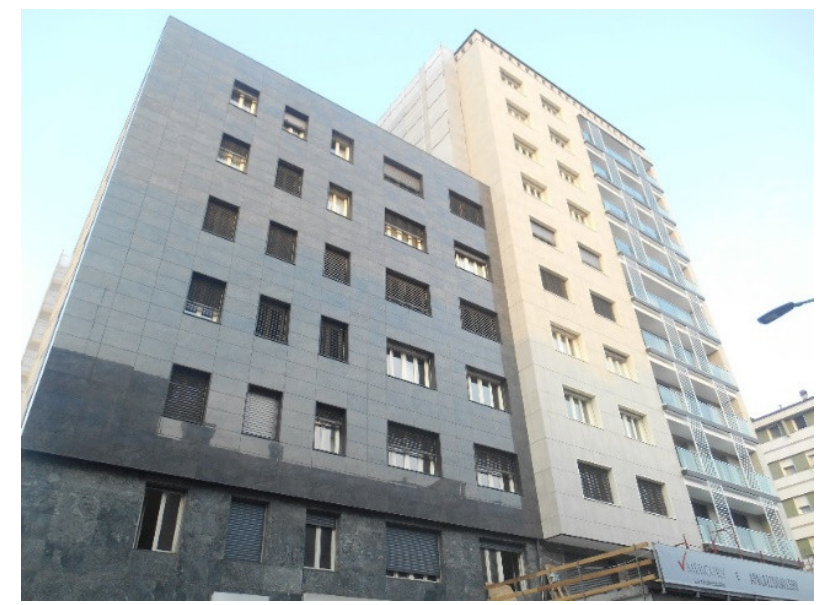

Figure 12. South-facing Block 1: on the left, the insulation and on the right, the ventilated façade are shown.

\section{Structural Design}

The structural analysis was developed following the need to secure the original facade in Botticino marble tesserae, suffering from a consistent pathology of deterioration and instability of the cladding (as reported in Section 4). Considering the age of the building, it was decided, through a multidisciplinary approach, to extend the study with a high-profile solution that would take into account not only the local rehabilitation of the structure, but also the global energy efficiency and the architecture of the "skin of the building", taking into account the constraints of the local Ministry of Cultural Heritage.

Of the two brick planks that make up the perimeter curtain walling, the inner one was left untouched, while the outer one, covered with tiles, was demolished, creating a structure with steel tubes hinged to the frame beams only, which was then curtain walled, leaving only the steel brackets ("little fins") bearing the hanging ventilated façade. The steel structure is deliberately not tied to the pillars (Figures 13 and 14).
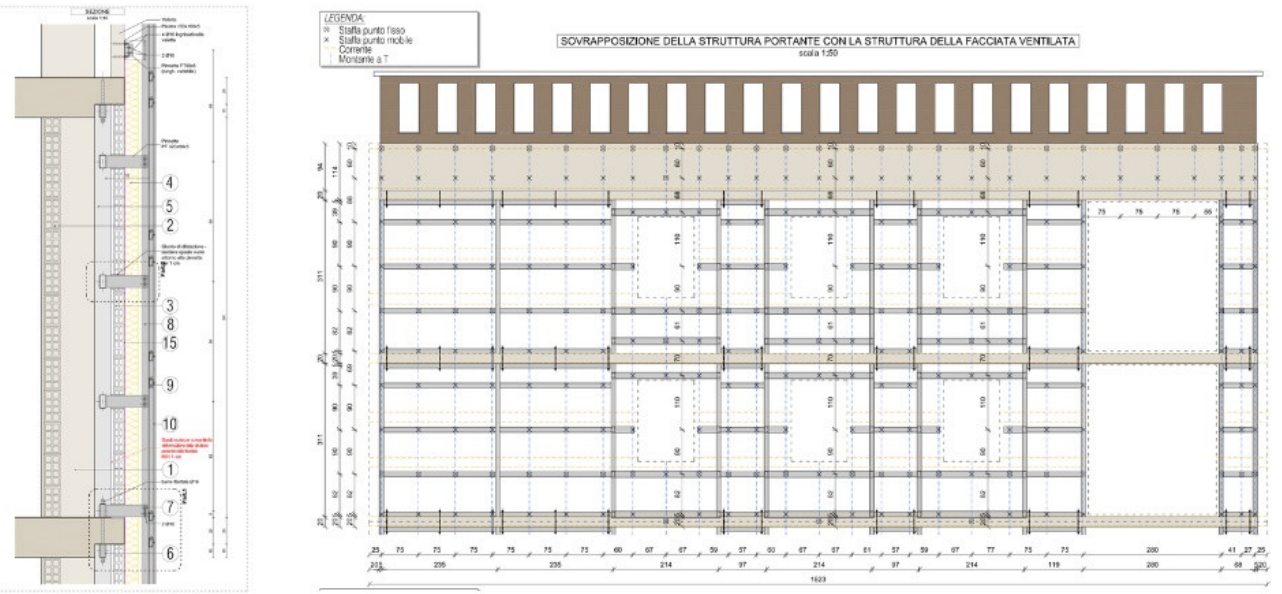

Figure 13. Tubular steel structure for the ventilated façade. 


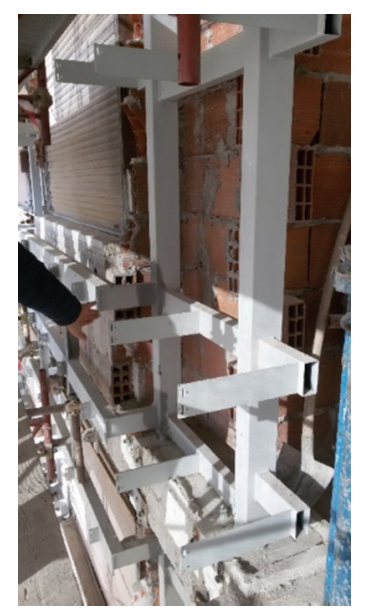

(a)

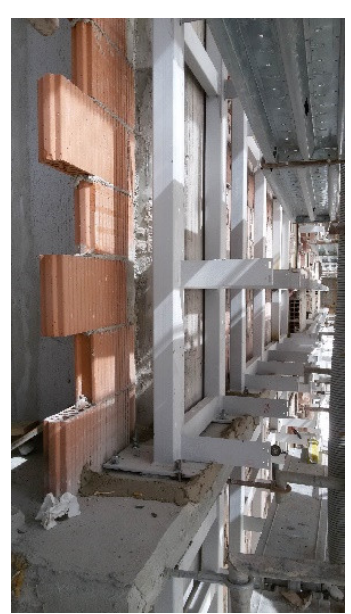

(b)

Figure 14. (a,b) Application of the tubular steel structure for the ventilated façade, where the "little fins" are visible.

This metal structure does not induce angular distortions in the building and increases local safety with no significant global effects, transmitting only vertical loads, which are actually reduced and overall less than $10 \%$ thanks to the careful choice of materials and application techniques.

Additional technological assemblies were placed in the cavity for the subsequent integration of systems and rock wool for thermal and acoustic insulation and fire protection (Figure 14). The previously removed infills were then reconstructed, consequently encapsulating the metal structure, with external application on the new planks of fibred anti-overturn systems, with local ante- and post-operam verification, rustic finishing and subsequent construction of the hanging ventilated wall.

\section{Seismic Evaluation of the Case Study}

At the time of the design, the building was in a category three seismic zone and, therefore, the actions had previously been calculated on the basis of the accelerations foreseen for that zone. When work began, new Regional provisions came into force that placed the Brescia town centre, and therefore, the buildings of interest, in a category two seismic zone, with the need to formally update the project and obtain seismic authorisation with the new input accelerations: $a_{g, \max }=0.154219$ according to [6].

The first verifications were carried out with the Midas Gen 2020 software, which proved to be most suitable for this type of analysis. The modelling was carried out by inserting the individual beam and column elements modelled as "Beam" elements to which the relative plastic hinges were then assigned (Figure 15).

The infills were only considered in the walls without openings because the method of equivalent struts was adopted, and they were modelled as "Truss" elements.

To the calculation model of the current state, the new load of the hanging ventilated facades was added as explained. To do this, the "Nodal Loads" command was followed, and the vertical load and moment produced by the brackets supporting the façade were entered.

The project status foresees a reinforcement/enhancement through the insertion of a deformable metal structure, anchored to the beams only, in anticipation of an increase in distributed masses concentrated for the anchorage of the ventilated façade with aluminium structure, for which a distributed load of $100 \mathrm{~kg} / \mathrm{m}^{2}$ is estimated.

The design state calculation model was achieved by implementing the additional facade load on the existing state model by simulating the load of the hanging ventilated facade (Figure 15b). The position of the new ventilated façade is at an angle, so possible distorting effects were sought, which were limited by the new inserted steel structure that 
tends to redistribute the eccentric load in a linear manner without distorting effects on the system.

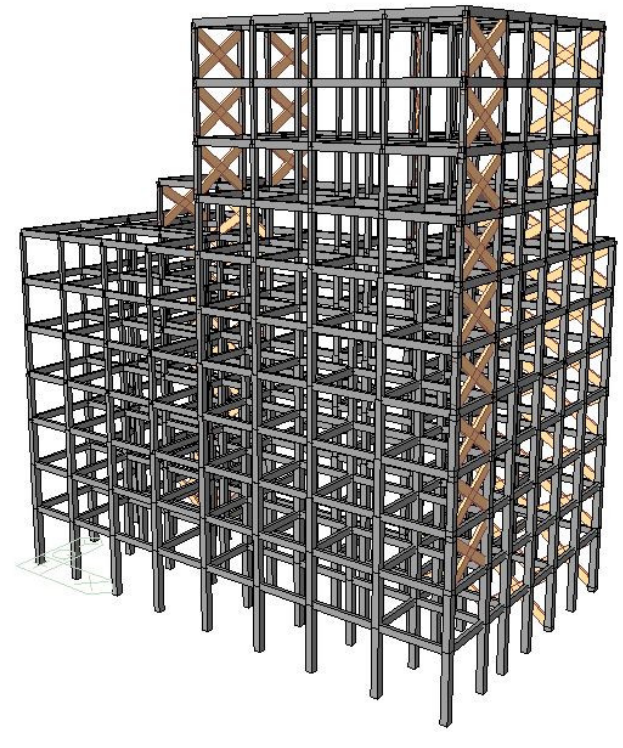

(a)

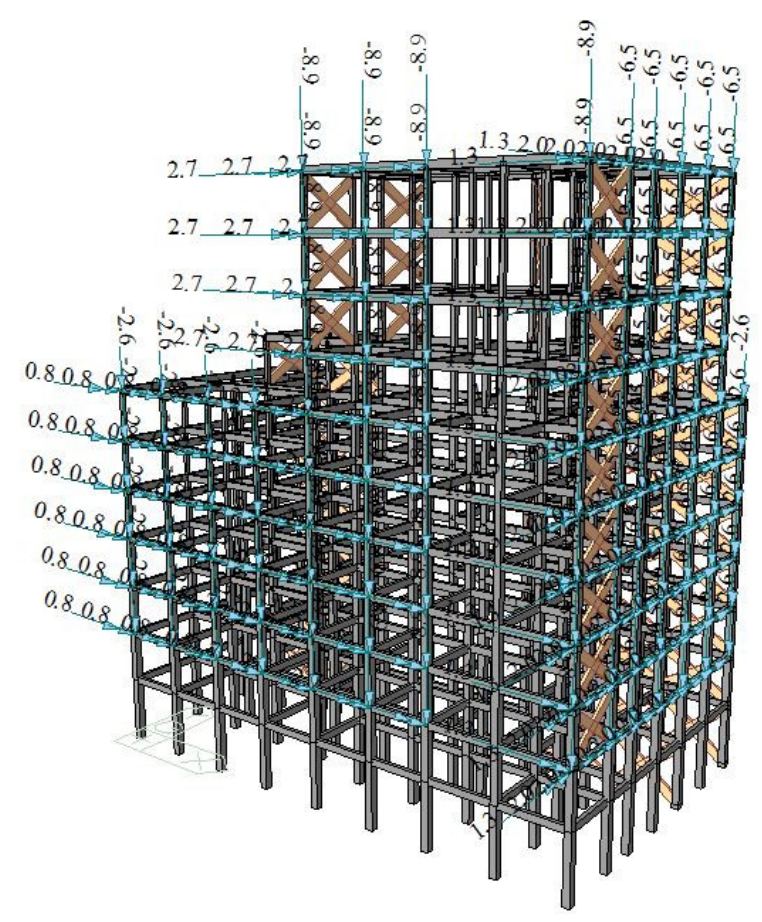

(b)

Figure 15. (a) Building model in the state before intervention and (b) building model project status with the nodal loads related to the weight of the new façade equal to $100 \mathrm{~kg} / \mathrm{m}^{2}$.

The seismic design was performed using a non-linear static analysis through the study and comparison of 24 push-over curves in the actual state and 24 push-over curves in the design state in order to evaluate the impact of the energy intervention on the building structures (Figure 16).

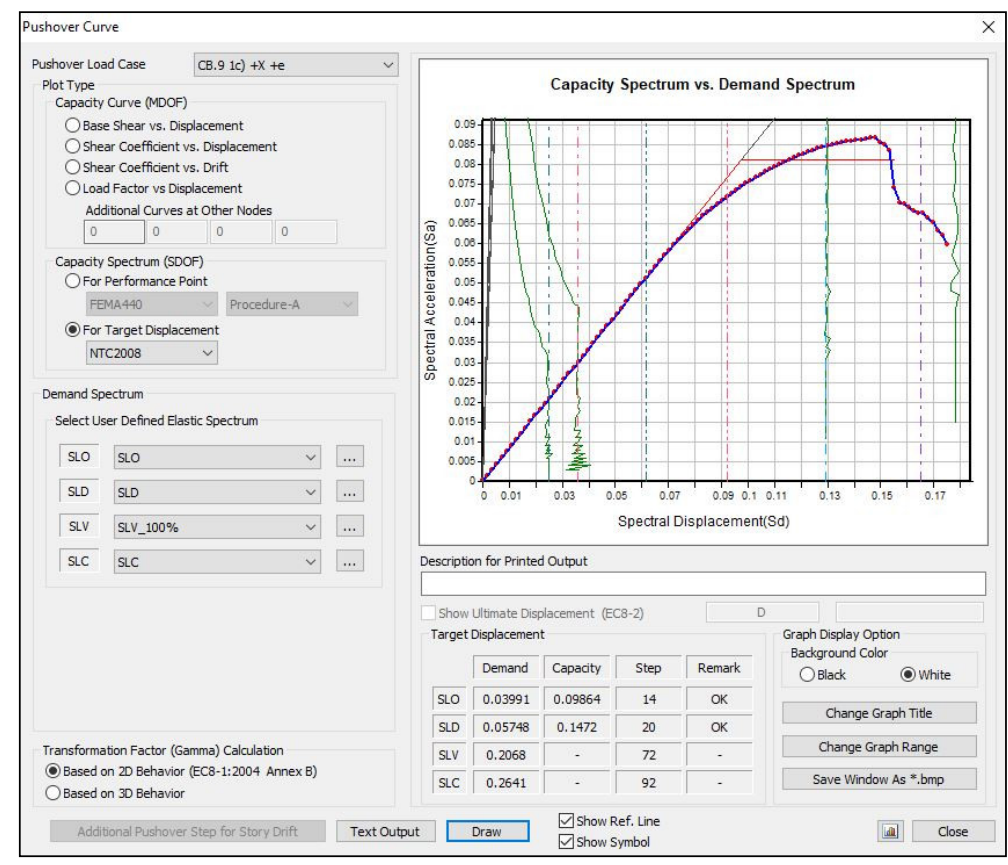

Figure 16. Example of a push-over curve used for analyses. 
In Table 4 , the results of the analysis carried out on the building before the intervention and in the design state are reported. The safety level of the construction is quantified through the $\zeta E$ value, the ratio between the maximum seismic action that can be borne by the structure and the maximum seismic action that would be used in the design of a new construction, while SLV means the ultimate limit state for safeguarding life (comparable to EC 8 Ultimate Limit State), SLD is the damage limit state.

Table 4. Results of the analysis carried out on the building before the intervention and in the design state.

\begin{tabular}{cc}
\hline \multicolumn{2}{c}{ Seismic Risk Indicators } \\
\hline Current State of the Building & Design State of the Building \\
\hline Global Indicators SLV & Global Indicators SLV \\
$\zeta$ E,SLV,DIR.X $=1.206$ & $\zeta \mathrm{E}, \mathrm{SLV}, \mathrm{DIR} . \mathrm{X}=1.192$ \\
$\zeta \mathrm{E}, \mathrm{SLV}, \mathrm{DIR} . \mathrm{Y}=1.217$ & $\zeta \mathrm{E}, \mathrm{SLV}, \mathrm{DIR} . \mathrm{Y}=1.218$ \\
\hline Local Indicators SLV & Local Indicators SLV \\
$\zeta \mathrm{E}, \mathrm{SLV}, \mathrm{DIR} . \mathrm{X}=1.000$ & $\zeta \mathrm{E}, \mathrm{SLV}, \mathrm{DIR} . \mathrm{X}=1.000$ \\
$\zeta \mathrm{E}, \mathrm{SLV}, \mathrm{DIR} . \mathrm{Y}=1.000$ & $\zeta \mathrm{E}, \mathrm{SLV}, \mathrm{DIR} . \mathrm{Y}=1.000$ \\
\hline
\end{tabular}

From the results of the analyses carried out on the design model (Table 4), it can be seen that at both SLV and SLD, all combinations have safety coefficients greater than one and, although slightly reduced, can be defined as substantially unchanged if compared to the actual state. This resulted in an intervention of local seismic improvement only. The deformable metal structure hinged with brackets to hang the ventilated façade does not induce angular distortions to the building, increasing local safety without any significant global effects, transmitting only vertical loads, which are in fact reduced and generally less than $10 \%$ due to the careful choice of materials and application techniques. An important aspect of the new metal façade support structure was to keep deformation under control to ensure compatibility between the support system and the new façade (Figure 17).
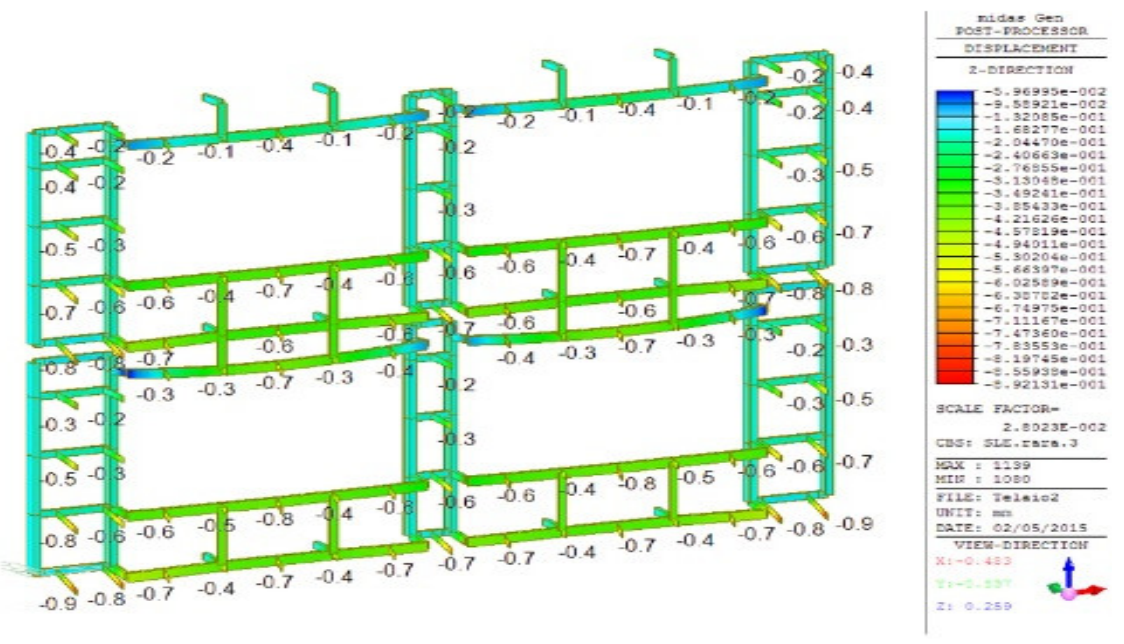

Figure 17. Analysis results-deformation in mm related to vertical displacements (Dz) of the new metal structure supporting the façade in the SLE-Rara3 combination.

The structural analysis carried out revealed the appropriateness of the building Structural Optimisation specifications contained in the GBC Condominiums protocol [1], thus highlighting their applicability in the context of existing residential buildings.

\section{Building Yard Management}

The project had to take into account that the building is owned by a single landlord, that it is used as offices and services (law offices, bank, bar, shops), and that it is located in 
the town centre of Brescia at a crossroads between two important traffic-intensive streets near Piazza della Vittoria. Therefore, the project necessarily had to take into account the need to reduce as much as possible any interference with the various activities of the tenants, keeping the execution time to a minimum, reducing the impact with vehicular and pedestrian flows and above all limiting the noise of the construction site at height, which was restricted by choice to agreed time periods right from the start of the project phase. In order not to obstruct normal traffic flow and to prevent access to the shops present, the scaffolding had to avoid reaching ground level, so a complex structure was built to allow traffic and pedestrians to circulate on the pavements.

Finally, the visual impact on the outside was also mitigated with greenery and a protective sheet with artistic decoration (Figure 18). These aspects of sustainable building yard management, implemented for this case study, confirmed that what is required by the GBC Condominiums "Sustainable Construction Site" prerequisite, in the relevant "Connection and Territory" section of the protocol, is applicable and results in a real mitigation of the impact of the construction site on the occupants and the surrounding area.

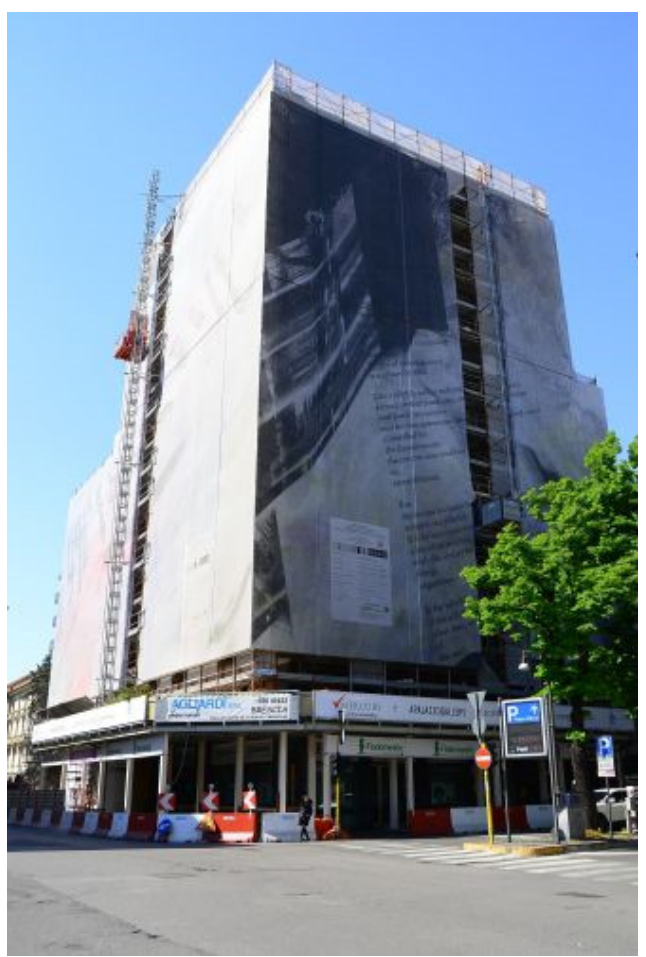

(a)

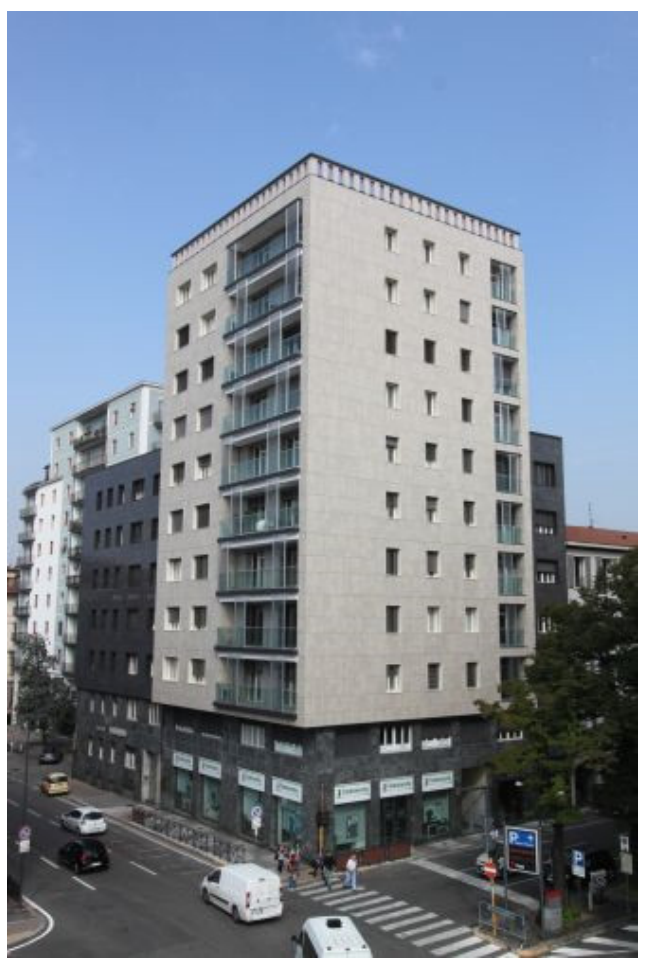

(b)

Figure 18. Tower building case study: (a) during the intervention, covered with an artistic sheet and (b) after the intervention.

The rehabilitation of existing buildings stocks requires an approach that allows the works to be carried out while allowing the occupants uninterrupted use of the units they occupy. It is, therefore, essential to draw up a "Construction Execution Plan" developed on the basis of the different needs for use and occupation of the building, which in the present case has ensured that any disputes or stoppage of the works are avoided. The site has always been open to guided site visits by university students (from Politecnico di Milano, University of Brescia, Master on Construction Innovation and Sustainable Engineering, Energy Management of Buildings, Province of Brescia Technical Office, ESEB Brescia, GBC).

\section{Conclusions}

The present study aimed to report a proper low-impact integrated study approach for the seismic and energy improvement of a tower building located in the centre of the city of 
Brescia, in the north of Italy, and in an area with a medium seismic hazard where strong earthquakes can occur (category two zone).

This was the first building in Italy in 2018 to be redeveloped with sustainability criteria verified, in parallel to their design and implementation, in accordance with the provisions of the GBC Condominiums protocol (version 1.0).

The main work phases can be briefly outlined as follows:

1. Preliminary technical feasibility study (diagnostic, structural, energy), preliminary checks;

2. Technical, economic, convenience, tax benefits, client capacity, economic optimisation and project financing evaluation study;

3. Executive diagnostic project (structural and energy);

4. Preliminary, final and executive design (architectural, structural, energy);

5. Optimisation of operational phases, site lay-out, safety;

6. Validation of the executive project;

7. Requests and permission, superintendence authorisation, filing for seismic authorisation (project carried out during the transitional phase, i.e., drawn up for zone three, then changed and filed for zone two);

8. Assistance for the contract, supervision of works, verifications in progress, accounting, testing.

The energy consumption, monitored one year after it became regular, has successfully turned out to be in line with the diagnosed previsions, with considerable savings in energetic and economic terms, which has made the interventions carried out worthwhile based on the methodology adopted.

This experience shows that the monitoring and behavioural analysis of a building, required by the GBC Condominiums protocol to maintain certification, is possible and makes it possible to make the most of the results obtained and guarantee performance over time.

From a structural point of view, a careful and scrupulous diagnostic investigation of the mechanical characteristics of the materials greatly contributed to the level of knowledge. Following a global verification of general orientation, carried out by means of a non-linear static analysis with the study and comparison of the 24 push-over curves ante and post operam, it was seen that the deformability progression of the building, with the additional new façade loads hanging from the existing structure, did not vary significantly in its global deformation behaviour, highlighting the compatibility of the energy intervention with the existing structures of the building given that the seismic risk indicators remain effectively unchanged.

We would like to conclude with a comment from the director of Green Building Council Italia, Eng. Marco Caffi, in which he declared that the contribution of this case study was fundamental to the development of the current version of the GBC Condominiums protocol and that it has maintained the structure of the initial version used here but has improved its applicability to both the preliminary analysis and the design and construction phases.

Author Contributions: Conceptualization, G.C., G.E.M. and D.R.; methodology, G.C., G.E.M. and D.R.; investigation, G.E.M. and D.R.; resources, G.E.M. and D.R.; data curation, G.E.M. and D.R.; writing-original draft preparation, G.C., G.E.M. and D.R.; writing-review and editing, G.C.; supervision, G.E.M. and D.R.; project design, G.E.M. and D.R. All authors have read and agreed to the published version of the manuscript.

Funding: This research received no external funding.

Institutional Review Board Statement: Not applicable.

Informed Consent Statement: Not applicable.

Data Availability Statement: Data sharing not applicable.

Acknowledgments: The authors wish to thank: Arch. Eng. G. Venturelli for the architectural project, Eng. E. Cattarina for his collaboration on the energy project and the GBC protocol, Eng. L. Fornoni 
for the fire prevention project and the systems, Eng. M. Piovanelli for the safety project and the building site, Eng. M. Baratti for his collaboration on the structural part, the Director of GBC ITALIA Eng. M. Caffi, B. Agliardi, owner of the Agliardi company, and the Technical Director Giovanni Ragni for the execution of the work. A heartfelt thank you to the entire Board of Directors of the Fondazione Zootecnica e Zooprofilassi di Brescia and in particular to the President Franco Bettoni for the trust placed in all the professionals appointed and the company carrying out the works. Finally, the authors would like to thank the Laboratories University Network of Seismic Engineering, project ReLUIS 2019-2021 from the Italian Civil Protection Department.

Conflicts of Interest: The authors declare no conflict of interest.

\section{References}

1. Geen Building Council Italia. Available online: https://www.gbcitalia.org/certificazione (accessed on 18 November 2020).

2. Robecchi, F. Egidio Dabbeni Ingegnere Architetto 1873-1964; Ed. Grafo: Brescia, Italy, 2014. (In Italian)

3. Settis, S.; Naffis-Sahely, A. If Venice Dies; New Vessel Press: New York, NY, USA, 2016.

4. Notizie Tecniche e Statistiche sulla Costruzione di Piazza della Vittoria, Architettura, Vol. 11 no. 12, Publisher: Treves-TreccaniTumminelli eds. Milan, Rome. December 1932, pp. 674-683. Available online: https://web.archive.org/web/20160407001535 /http: / / www.casadellarchitettura.eu/fascicolo/data/2010-12-20_384_744.pdf (accessed on 18 November 2020). (In Italian).

5. OPCM n. 327420 March 2003, Ordinance of the President of the Council of Ministers, (G.U. n. 105 del 8/05/2003), Primi Elementi in Materia di Criteri Generali per la Classificazione Sismica del Territorio Nazionale e Normative Tecniche per le Costruzioni in Zona Sismica; IL Presidente del Consiglio dei Ministri: Rome, Italy, 2003. (In Italian)

6. D.G.R. 11 July 2014-n. X/2129, Aggiornamento delle Zone sismiche in Regione Lombardia (l.r. 1/2000, art. 3, c. 108, lett. d); Deliberation of the Regional Council of Lombardy: Milan, Italy, 2004. (In Italian)

7. Pivato, E. Breve Storia di via Antonio Gramsci, Urban Center Brescia-Laboratorio di Cultura Urbana, Comune di Brescia. 18 September 2019. Available online: https://www.comune.brescia.it/servizi/urbancenter/assemblee/Documents/190918_UC_ AT_166-Breve\%20storia\%20di\%20via\%20Gramsci.pdf (accessed on 18 November 2020). (In Italian).

8. National Code, D.M. 14-1-2008 NTC2008, (New Technical Standards for Construction). In Nuove norme Tecniche per le Costruzioni; G. U. n. 29 del 4 febbraio 2008, S.O 2018; IL Capo Dipartimental Della Protezione Civile: Rome, Italy, 2018. (In Italian)

9. Sbaffoni, S.; Beltrani, T.; Cutaia, L.; Santino, D.; Martini, F. Diagnosi energetica e diagnosi delle risorse. In Energia, Ambiente ed Innovazione; ENEA Magazin: Rome, Italy, 2019; Volume 3, pp. 115-117, (In Italian). [CrossRef]

10. DGR 22 December 2008-n.8745. Determinazioni in Merito alle Disposizioni di Efficienza Energetica in Edilizia e per la Certificazione Energetica degli Edifici; Deliberation of the Regional Council of Lombardy: Milan, Italy, 2008. (In Italian)

11. DM 26/6/2015, Interministerial Decree of 26 June 2015. Adaptation of National Guidelines for the Energy Certification of Buildings) Adeguamento linee Guida Nazionali per la Certificazione Energetica degli Edifice; Ministero Dello Sviluppo Economico: Rome, Italy, 2015. (In Italian)

12. UNI EN ISO 10211:2008. Ponti Termici in Edilizia—Flussi Termici e Temperature Superficiali_Calcoli Dettagliati, Thermal Bridges in Building Construction-Heat Flows and Surface Temperatures—Detailed Calculations; Associazione Italiana Polistirene Espanso: Milan, Italy, 2018; withdrawn with replacement.

13. UNI EN ISO 9712:2012. Prove non distruttive-Qualificazione e certificazione del personale addetto alle prove non distruttive. Nondestructive testing-Qualification and certification of NDT personnel; Associazione Italiana Polistirene Espanso: Milan, Italy, 2012.

14. UNI 10349:2016. Heating and Cooling of Buildings—Climate Data-Part 1. Riscaldamento e Raffrescamento degli edifici-Dati climaticiParte 1: Medie mensili per la valutazione della prestazione termo-energetica dell'edificio e metodi per ripartire l'irradianza solare nella frazione diretta e diffusa e per calcolare l'irradianza solare su di una superficie inclinata; Associazione Italiana Polistirene Espanso: Milan, Italy, 2016. (In Italian)

15. Corpo Nazionale dei Vigili del Fuoco prot. n. 0005043 del 15/04/2013-Oggetto: GUIDA TECNICA su "Requisiti di sicurezza antincendio delle facciate negli edifici civili"; Dipartimento dei Vigili del Fuoco, del Soccorso Pubblico e della Difesa Civile Direzione Centrale per la Prevenzione e la Sicurezza Tecnica: Rome, Italy, 2013. (In Italian)

16. DGR 30 July 2015-n.6480. Disposizioni in merito alla Disciplina per L'efficienza Energetica degli Edifici e per il Relativo Attestato di Prestazione Energetica a Seguito della DGR 3868 del 17/07/2015; Deliberation of the Regional Council of Lombardy: Milan, Italy, 2015. (In Italian) 